\title{
Adult T-cell leukemia/lymphoma in the Caribbean cohort is a distinct clinical entity with dismal response to conventional chemotherapy
}

\author{
Monica Zell 1,* , Amer Assal2, ${ }^{*}$, Olga Derman², Noah Kornblum², Ramakrishna Battini², \\ Yanhua Wang ${ }^{3}$, Deepa M. Narasimhuluํ, Ioannis Mantzaris², Aditi Shastri ${ }^{2}$, Amit \\ Verma $^{2}$, Hilda $\mathrm{Ye}^{4}$, Ira Braunschweig ${ }^{2}$, Murali Janakiram² \\ ${ }^{1}$ Albert Einstein College of Medicine, Bronx, NY, USA \\ ${ }^{2}$ Department of Oncology, Montefiore Medical Center/ Albert Einstein College of Medicine, Bronx, NY, USA \\ ${ }^{3}$ Department of Pathology, Montefiore Medical Center/ Albert Einstein College of Medicine, Bronx, NY, USA \\ ${ }^{4}$ Department of Cell Biology, Albert Einstein College of Medicine, Bronx, NY, USA \\ *These authors have contributed equally to this work \\ Correspondence to: Murali Janakiram, email: mjanakir06@gmail.com \\ Keywords: human T-cell lymphotropic virus type-1 (HTLV-1), adult T-cell leukemia/lymphoma (ATLL), non-Hodgkin lymphoma, T-cell \\ lymphoma, allogeneic stem cell transplantation \\ Received: January 27, $2016 \quad$ Accepted: May 09, $2016 \quad$ Published: June 22, 2016
}

\section{ABSTRACT}

Adult T-cell leukemia/lymphoma (ATLL) is a rare and aggressive disease caused by human T-cell lymphotropic virus type 1 that predominantly affects Japanese and Caribbean populations. Most studies have focused on Japanese cohorts. We conducted a retrospective analysis of 53 cases of ATLL who presented to our institution between 2003-2014. ATLL in the Caribbean population presents more often as the acute and lymphomatous subtypes, is associated with complex cytogenetics, and has a high rate of CNS involvement. The overall response rate to first-line therapies with anthracycline-based regimens was poor $(32 \%)$, with a median survival of only $\mathbf{6 . 9}$ months. A complete or partial response to first-line regimens was associated with better survival. There was no difference in survival between patients who received chemotherapy alone versus chemotherapy with antiviral agents. Allogeneic transplantation was performed in five patients, two of whom achieved complete remission despite residual or refractory disease. Recipients of allogeneic transplantation had significantly improved overall survival compared to non-transplanted patients. This is the first analysis to describe ATLL pathological features, cytogenetics, and response to standard therapy and transplantation in the Caribbean cohort.

\section{INTRODUCTION}

Adult T-cell leukemia/lymphoma (ATLL) is a rare mature T-cell malignancy first described in Japan in 1977 [1]. The causative agent of ATLL has been identified as the human T cell lymphotropic virus type 1 (HTLV-1) [2-4], which is endemic to Japan, the Caribbean islands, Central and South America, and parts of sub-Saharan Africa [5]. Prevalence in the United States reflects emigration patterns of individuals from endemic areas. ATLL develops in approximately $5 \%$ of HTLV-1 infected individuals who acquire the virus via vertical transmission [5].
The pathogenesis of ATLL in HTLV-1-infected individuals may differ from one population to another. In a comparison between Japanese and Caribbean cohorts, Japanese patients displayed a higher incidence of ATLL, male predominance, and older peak age of onset [6]. Another study demonstrated differences in ATLL disease development, where antibody titers and anti-tax antibody, both markers of strong immune response and viral replication and the latter, an antibody to a viral protein involved in ATLL pathogenesis [7], were higher in Jamaican subjects [6]. In contrast, a high viral load with low antibody titers was found in Japanese subjects, which 
is a pattern consistent with high risk for ATLL. Clinically, ATLL is divided into four distinct subtypes based on the Shimoyama diagnostic criteria: acute, lymphomatous, chronic, and smoldering [8]. The acute and lymphomatous subtypes have poorer prognosis and survival [8]. Major prognostic factors associated with a shorter survival in all types of ATLL include elevated lactate dehydrogenase (LDH) level, advanced age, greater than three involved lesions, hypercalcemia, poor performance status, serum albumin $<3.5 \mathrm{~g} / \mathrm{dL}$, and sIL-2R $>20,000 \mathrm{U} / \mathrm{mL}$ [9-11]. Although there is no specific karyotypic or molecular abnormality in ATLL, many common cytogenetic abnormalities have been described in Japanese studies [12-14]. There have been no large series analyzing cytogenetic findings in Caribbean patients.

Survival of ATLL patients remains poor despite therapy. The regimen with the best outcomes as reported in a randomized trial by the Japanese Clinical Oncology Group (JCOG) is VCAP-AMP-VECP (vincristine, cyclophosphamide, doxorubicin, and prednisone (VCAP), doxorubicin, ranimustine, and prednisone (AMP), and vindesine, etoposide, carboplatin, and prednisone (VECP)), also known as LSG15 [15]. When compared to CHOP administered biweekly, a higher response rate was noted ( $40 \%$ versus $25 \%, \mathrm{p}=0.02)$, as well as a trend for higher three-year survival $(24 \%$ versus $13 \%, \mathrm{p}=0.085)$. The use of this regimen has been limited in the United States, and the National Comprehensive Cancer Network (NCCN) guidelines recommend regimens typically used in other non-Hodgkin lymphomas (NHL) such as CHOP, CHOEP, and dose-adjusted EPOCH [16]. While still not a standard of care, allogeneic hematopoietic stem cell transplantation can be considered [17-19], while the use of autologous stem cell transplantation is not recommended $[17,20]$.

Given the limited scope of published data on Caribbean ATLL, a current and complete description is needed to further characterize the nature of this entity as distinct from the Japanese variant. We report the clinicopathologic features, treatment patterns, and disease outcomes of ATLL in a large, predominantly Caribbean cohort from a single institution in Bronx, New York.

\section{RESULTS}

\section{Demographic and baseline data}

We identified 53 cases of ATLL treated at Montefiore Medical Center between 2003 - 2014 [Table 1]. Median age at presentation was 54 years (range 28-87), with a female predominance $(62 \%)$. Our cohort almost entirely represents "western" ATLL, with $91 \%$ of patients of Caribbean or Latin origin $(n=48)$; the remaining five patients were of African origin. No patients were of nonHispanic Caucasian ethnicity or Asian descent.

Based on the Shimoyama classification, 36 (68\%) patients had acute subtype, 14 (26\%) had lymphomatous, and three $(6 \%)$ had chronic/smoldering disease. Patients presented with generalized lymphadenopathy (77\%), bone marrow involvement (58\%), hepatosplenomegaly (57\%), skin $(30 \%)$, lung $(21 \%)$, gastro-intestinal $(17 \%)$, or bone lesions (14\%). Of the 27 patients whose CSF was tested for CNS involvement at presentation, nine were positive (33\%). Patients with acute and chronic subtypes tended to present with lymphocytosis $(51 \%)$ with a mean value of 17,490 (600 - 193,000) cells/microliter. Elevated LDH was seen in all patients with a mean value of 1299 (252 9610) units/L. Hypercalcemia was also a common feature $(64 \%)$, with a mean value of $12.03(7.4-20) \mathrm{mg} / \mathrm{dL}$. Of the patients tested for HIV $(70 \%)$, none were positive. The majority of patients had the classic CD4+/CD8- CD25+ ATLL immunophenotype (83\%), while fewer had an atypical phenotype (CD4+/CD8+ or CD4-/CD8-) (17\%).

Of 53 total patients, $15(28 \%)$ had positive CSF cytology and/or flow cytometry at any time during their disease. Three had clinical CNS symptoms (20\%), and five had evidence of CNS disease on radiographic imaging (33\%) [Table 2]; all patients with CNS symptoms had positive radiographic findings.

Out of 22 patients tested for cytogenetic abberations, 10 had complex karyotypes, and three patients had abnormalities limited to one chromosome [Table 3]. Aneuploidy of several chromosomes was noted including $+3,-4,-6,-7,+7,+8,-9,-10$, $-11,-12,-13,-14,+14,-15,-16,-17,-19,+19,-20$, $+20,+21,-22,+22,+\mathrm{X}$, and $-\mathrm{Y}$. Deletions affecting chromosomes $1,3,5,6,7,8,9,11,12$, and 20 were noted. The most commonly affected chromosome was 14 , with abnormalities found in eight patients, followed by chromosomes $1,9,11$, and 20, with abnormalities found in six patients each. Recurrent deletions noted were deletion 3q21, 5q33, and 20q11.2. Recurrent loci affected by additions or duplications included $2 \mathrm{p} 11.2$ and $14 q 32$. Recurrent loci affected by translocation or addition included 1q21, 7q36 (one translocation and one addition), 9p13 (one translocation and one addition), $11 \mathrm{q} 13$ (one translocation and one duplication), 14q10 (one translocation and one inversion), 19p13.3 (one translocation and one addition), and 20q11.2 (one translocation, one addition and one deletion). Seven patients also had additional unidentified chromosomes.

\section{Therapy and survival}

Outcomes with front-line therapy for patients with acute or lymphomatous subtype were poor [Table 4]. Most patients $(n=42,79 \%)$ received first-line treatment, whereas $17 \%(n=9)$ were not treated due to poor performance status, and two patients were lost to follow up after diagnosis. The median age of patients who received treatment was 46 years, while those who were not treated due to comorbidities had a median age of 75 years. One patient with chronic subtype disease received first-line treatment with interferon alpha + zidovudine 
Table 1: Patient demographics and baseline clinical features

Characteristic

Age at diagnosis (yrs)

40 or less

$41-60$

61 or greater

Gender

Female

Male

Geographic Origin

Caribbean/Hispanic

African

ATLL Subtype

Acute

Lymphomatous

Chronic

Smoldering

Symptoms and pathological features

Lymphadenopathy

Rash

Pleural Effusion

Ascites

Bone Marrow Involvement (40)

Bone Lesions (51) ${ }^{\mathrm{a}}$

CNS Involvement (27)

Hypercalcemia

Lymphocytosis

Abnormal cytogenetics (22) ${ }^{\mathrm{a}}$

Immunophenotype

Typical (CD4+/CD8-)

Atypical (CD4+/CD8+ or CD4-/CD8-)
$36(68 \%)$

$44(83 \%)$

Total frequency $(\%)$

$11(21 \%)$

$24(45 \%)$

$18(34 \%)$

$33(62 \%)$

$20(38 \%)$

48 (91\%)

$5(9 \%)$

$14(26 \%)$

$3(6 \%)$

$0(0.0 \%)$

$41(77 \%)$

$16(30 \%)$

$21(40 \%)$

$11(21 \%)$

$31(78 \%)$

7 (14\%)

$9(33 \%)$

31 (59\%)

27 (51\%)

$13(59 \%)$

$9(17 \%)$

a Total number of patients tested for this variable in parentheses.

$(n=53)$.

$($ IFN + AZT) and achieved complete remission. Among patients with acute or lymphomatous subtype $(n=41)$, chemotherapy alone was given to 23 patients $(56 \%)$ with an overall response rate (ORR) of 30\%. Regimens included EPOCH $(n=11)$, CHOP $(n=7)$, Hyper CVAD $(n=4)$, and CVP $(n=1)$. Chemotherapy with antiviral therapy was administered to 16 patients (39\%) with an ORR of $38 \%$. The most common chemotherapy regimen in this group was EPOCH $(n=14)$, while the most common antiviral agents used were lamivudine/zidovudine $(n=8)$, followed by raltegravir $(n=5)$, zidovudine $(n=2)$, and lamivudine $(n=1)$. Two patients were treated with IFN + AZT $(5 \%)$ alone, with one patient maintaining stable disease over three months, and one with progressive disease. The ORR after first-line therapy for patients with acute or lymphomatous subtype was $32 \%$; nine patients $(22 \%)$ achieved a CR, four patients $(10 \%)$ achieved a PR, and eight patients (20\%) died. Median duration of response was 171 days after first-line therapy. Of the remaining patients with primary refractory, progressive 
Table 2: Features of patients with CNS disease

\begin{tabular}{|c|c|c|c|}
\hline Patient & $\begin{array}{l}\text { CNS } \\
\text { Symptoms }\end{array}$ & CSF Flow cytometry / Cytology & $\begin{array}{l}\text { Imaging at time of } \mathrm{CNS} \\
\text { disease }\end{array}$ \\
\hline 1 & None & $\begin{array}{l}\text { Paucicellular cytospin specimen with rare atypical } \\
\text { lymphocytes }\end{array}$ & CT head - Negative \\
\hline 2 & None & $\mathrm{CD} 4+, \mathrm{CD} 25+, \mathrm{CD} 7-, \mathrm{CD} 26-$ & CT head - Negative \\
\hline 3 & $\begin{array}{l}\text { Cranial nerve } \\
\text { palsy }\end{array}$ & $\mathrm{CD} 3+, \mathrm{CD} 4+, \mathrm{CD} 25+, \mathrm{CD} 27+, \mathrm{CD} 7-, \mathrm{CD} 26-$ & $\begin{array}{l}\text { MRI Brain - Diffuse dural } \\
\text { thickening }\end{array}$ \\
\hline 4 & None & $\mathrm{CD} 2+, \mathrm{CD} 3+, \mathrm{CD} 4+, \mathrm{CD} 5+, \mathrm{CD} 7-$ & CT head - Negative \\
\hline 5 & None & $\begin{array}{l}23 \% \text { CD } 4+\text { T-cells with reduced CD7 expression, partial } \\
\text { expression of CD } 25\end{array}$ & CT head-Negative \\
\hline 6 & None & Positive for malignant cells, & $\begin{array}{l}\text { MRI head-Meningeal } \\
\text { enhancement }\end{array}$ \\
\hline 7 & None & Abnormal CD4+ T-cells that lack CD7 & CT Head - Negative \\
\hline 8 & Headache & Positive for malignant cells & $\begin{array}{l}\text { CT head-Right frontal skull } \\
\text { lesion with dehiscence } \\
\text { of the inner table, with } \\
\text { a minimal epidural } \\
\text { component }\end{array}$ \\
\hline 9 & None & $\mathrm{CD} 2+, \mathrm{CD} 3+, \mathrm{CD} 4+, \mathrm{CD} 5+, \mathrm{CD} 8+, \mathrm{CD} 7-$ & MRI Brain - Normal \\
\hline 10 & None & $\mathrm{CD} 4+, \mathrm{CD} 25+, \mathrm{CD} 7-$ phenotype & $\begin{array}{l}\text { MRI Brain - Faint thin } \\
\text { dural enhancement }\end{array}$ \\
\hline 11 & None & CD4+, CD25+ T-cells & CT head - Negative \\
\hline 12 & Headache & $0.6 \% \mathrm{CD} 3+, \mathrm{CD} 4+, \mathrm{CD} 7-, \mathrm{CD} 25+\mathrm{T}$-cells & $\begin{array}{l}\text { MRI Brain - Large } \\
\text { destructive sinonasal mass, } \\
\text { extension to adjacent } \\
\text { structures. Parameningeal } \\
\text { extension. }\end{array}$ \\
\hline 13 & None & $\mathrm{CD} 2+, \mathrm{CD} 7+, \mathrm{CD} 3+, \mathrm{CD} 5+, \mathrm{CD} 4-, \mathrm{CD} 8-$ & CT head - Negative \\
\hline 14 & None & $9 \%$ T-cells CD4+, CD7-, mostly CD25+ & CT head - Negative \\
\hline 15 & None & Atypical. Scattered lymphocytes, some with mild atypia. & CT head - Negative \\
\hline
\end{tabular}

CNS: central nervous system; CSF: cerebral spinal fluid; CT: computed tomography; MRI: magnetic resonance imaging. $(n=15)$.

disease, or relapse $(n=39), 56 \%(n=22)$ went on to receive second-line therapy, where only two patients $(9 \%)$ achieved a response. The most common second-line therapy regimens were hyper $\operatorname{CVAD}(n=5)$ and $\operatorname{ICE}(n=4)$.

\section{Stem cell transplantation}

A total of seven patients were treated with hematopoietic stem cell transplantation in our cohort. Autologous transplantation was performed in two chemotherapy-sensitive patients, one with acute subtype and one with lymphomatous, as a consolidation therapy after firstline anthracycline-based chemotherapy (EPOCH and CHOP, respectively). Both patients received BEAM conditioning (carmustine, etoposide, cytarabine, and melphalan). The progression free survival (PFS) after autologous transplant was 13 months and nine months, respectively, with overall survival of 19.8 and 18.5 months, respectively.

Allogeneic hematopoietic stem cell transplantation (allo-HSCT) was performed in five patients [Table 5]. ATLL subtypes of transplanted patients included four acute and one lymphomatous. At the time of transplantation, one patient was in CR, three were in PR, and one had primary refractory disease. Three patients had a matched related donor, one patient a matched unrelated donor, and one a haploidentical donor. After allo-HSCT, two patients achieved a CR and remain in remission at the time of this report, while three patients died. Of those three patients, all died within 100 days of their transplant, with two due to progressive disease and one due to Grade 4 graft versus host disease (GVHD) after immunosuppression withdrawal for disease recurrence. 
Table 3: Cytogenetic findings in tested patients with ATLL

\begin{tabular}{|c|c|c|c|}
\hline Subtype & $\begin{array}{l}\text { Age/ } \\
\text { Gender }\end{array}$ & Source & Karyotype \\
\hline Acute & $39 / \mathrm{F}$ & $\mathrm{BM}$ & $\begin{array}{l}48 \sim 49, X X,+X, \operatorname{del}(1)(\mathrm{p} 34), \operatorname{add}(2)(\mathrm{p} 11.2), \operatorname{del}(3)(\mathrm{q} 21), \operatorname{dic}(3: 3)(\mathrm{q} 21 ; \mathrm{p} 21) \\
\operatorname{del}(5)(\mathrm{q} 13 \mathrm{q} 33), \operatorname{del}(7)(\mathrm{p} 13),+8, \operatorname{del}(9)(\mathrm{p} 13), \operatorname{dup}(11)(\mathrm{q} 13 \mathrm{q} 23),-12,-15,-16, \\
-17, \operatorname{add}(19)(\mathrm{p} 13.3),-20,+22\end{array}$ \\
\hline Acute & $42 / \mathrm{M}$ & $\mathrm{BM}$ & $44, \mathrm{X},-\mathrm{Y},-6, \operatorname{der}(13) \mathrm{t}(13 ; 14)(\mathrm{q} 10 ; \mathrm{q} 10),+\operatorname{mar}$ \\
\hline Acute & $69 / \mathrm{M}$ & $\mathrm{BM}$ & $\begin{array}{l}48 \sim 49, X Y,+X, t(1 ; 7)(\mathrm{q} 32 ; \mathrm{q} 36), \operatorname{add}(9)(\mathrm{p} 24), \mathrm{t}(11 ; 19)(\mathrm{q} 13 ; \mathrm{p} 13.3), \operatorname{add}(14) \\
(\mathrm{p} 10),+14, \operatorname{add}(20)(\mathrm{q} 11.2), \operatorname{del}(20)(\mathrm{q} 11.2),+20\end{array}$ \\
\hline Acute & $35 / \mathrm{M}$ & PB & $\begin{array}{l}45 \sim 48, X,-Y, \operatorname{der}(1) \mathrm{t}(1 ; 10)(\mathrm{q} 21 ; \mathrm{p} 11.2), \mathrm{t}(1 ; 11)(\mathrm{q} 22 ; \mathrm{q} 24),+\operatorname{der}(1) \operatorname{del}(1) \\
(\mathrm{q} 21 \mathrm{q} 42),+3,-4, \operatorname{del}(6)(\mathrm{q} 13 \mathrm{q} 22), \operatorname{add}(7)(\mathrm{q} 36), \operatorname{del}(8)(\mathrm{q} 22 \mathrm{q} 24.3),-10, \operatorname{add}(12) \\
(\mathrm{q} 24.3),+\operatorname{del}(12)(\mathrm{q} 13 \mathrm{q} 14),-14,-15,-16,-17,-19,-20,+21,+21,+22,+22, \\
+2 \mathrm{mar}\end{array}$ \\
\hline Acute & $51 / \mathrm{M}$ & $\mathrm{BM}$ & $46, X Y, \operatorname{del}(11)(q 23)$ \\
\hline Acute & $44 / \mathrm{M}$ & $\mathrm{BM}$ & 46, Y, t $(\mathrm{X} ; 9)(\mathrm{p} 22.1 ; \mathrm{p} 13), \mathrm{t}(1 ; 20)(\mathrm{p} 22 ; \mathrm{q} 11.2), \mathrm{t}(2 ; 15)(\mathrm{q} 33 ; \mathrm{p} 12)$ \\
\hline Acute & $60 / \mathrm{F}$ & $\mathrm{BM}$ & $46, \mathrm{XX}, 14 q 11.2$ and $14 q 32$ polysomy on $\mathrm{FISH}^{\mathrm{a}}$ \\
\hline Acute & $36 / \mathrm{M}$ & $\mathrm{BM}$ & $\begin{array}{l}47-48, \text { XY, der(2)t }(1 ; 2)(\mathrm{q} 21 ; \mathrm{q} 35), \operatorname{add}(3)(\mathrm{p} 21), \operatorname{del}(3)(\mathrm{q} 21),+3, \operatorname{del}(6)(\mathrm{q} 23), \\
-9,-9,-10, \text { add }(14)(\mathrm{q} 32),+1-3 \operatorname{mar}\end{array}$ \\
\hline Acute & $43 / \mathrm{M}$ & PB & $48, \mathrm{XY}, \operatorname{del}(6)(\mathrm{p} 22),+7,+14,-17,+3 \operatorname{mar}$ \\
\hline Acute & $58 / \mathrm{F}$ & $\mathrm{BM}$ & $\begin{array}{l}47, X X, t(1 ; 13)(p 36.3 ; q 33), \operatorname{dup}(2)(\mathrm{p} 11.2 \mathrm{p} 14), \mathrm{t}(4: 9)(\mathrm{q} 34 ; \mathrm{q} 31.1), \mathrm{t}(15 ; 19) \\
(\mathrm{p} 11.2 ; \mathrm{q} 13.2),+19\end{array}$ \\
\hline Acute & $54 / \mathrm{F}$ & $\mathrm{BM}$ & $\begin{array}{l}84 \sim 85, X X, \operatorname{add}(3)(\mathrm{q} 12) \times 2,+3, \operatorname{add}(4)(\mathrm{q} 31),-4, \operatorname{del}(5)(\mathrm{q} 15 \mathrm{q} 33) \times 2,-7, \operatorname{add}(9) \\
(\mathrm{p} 13) \times 2,-10,-10,-11, \operatorname{add}(11)(\mathrm{p} 15),-12,-13,-13,-13, \operatorname{add}(13)(\mathrm{p} 10),-14, \\
\mathrm{i}(14)(\mathrm{q} 10),-15, \operatorname{add}(15)(\mathrm{p} 10),-19,-19,-20, \operatorname{add}(20)(\mathrm{q} 13.3) \times 2, \mathrm{i}(21)(\mathrm{q} 10) \times 2 \\
+10 \mathrm{mar}\end{array}$ \\
\hline Acute & $56 / \mathrm{F}$ & $\mathrm{BM}$ & $\begin{array}{l}45-46, X, \operatorname{add}(X)(\mathrm{q} 22), \mathrm{t}(11 ; 15)(\mathrm{p} 11.2 ; \mathrm{q} 12), \operatorname{del}(12)(\mathrm{p} 12), \operatorname{add}(14)(\mathrm{p} 11.2), \\
-16,-17,-22,+ \text { mar }\end{array}$ \\
\hline Lymphomatous & $62 / F$ & $\mathrm{BM}$ & $46, X X, \operatorname{del}(20)(q 11, .2)$ \\
\hline
\end{tabular}

${ }^{a}$ Fluorescent in situ hybridization, this patient had a history of Philadelphia chromosome positive chronic myelogenous leukemia.

BM: bone marrow; PB: peripheral blood.

$(\mathrm{n}=13)$.

\section{Overall survival}

The median overall survival (OS) was 6.9 months [Figure 1]. There was no significant difference in survival between patients who received chemotherapy versus chemotherapy with an antiviral agent $(\mathrm{p}=0.94)$ [Figure $1 b]$. Since EPOCH is the most commonly used regimen for ATLL in the United States, we compared survival after therapy with EPOCH-based regimens versus all other regimens and found no statistically significant difference in $\mathrm{OS}(\mathrm{p}=0.21)$. The response to first-line therapy impacted survival, with those achieving partial (PR) or complete response $(\mathrm{CR})$ experiencing better $\mathrm{OS}(\mathrm{p}<0.01)$ [Figure 1c]. Compared to those who did not receive an allo-HSCT, a significant increase in OS was observed in allo-HSCT recipients $(\mathrm{p}=0.02)$ [Figure $1 \mathrm{~d}]$.

\section{DISCUSSION}

In this study we outline a tertiary medical center's experience with ATLL, a rare, poor-risk disease with a high mortality rate. Montefiore Medical Center (MMC) in the Bronx serves a large urban population, with many immigrants and descendants of immigrants from the Caribbean. The significant volume of ATLL cases encountered at MMC makes our institution one of the primary centers to diagnose and treat ATLL in the United States. Since most of these patients are from the Caribbean Basin, our experience closely reflects the ATLL experience from that part of the world. This study reveals diagnostic and therapeutic challenges as well as actuarial efficacy of currently accepted treatment strategies. Our study is 
Table 4: Front-line therapy and response rates in patients with acute or lymphomatous subtypes

\begin{tabular}{lcc}
\hline \multicolumn{1}{c}{ Therapy } & Number & Overall Response Rate (\%) \\
\hline Chemotherapy Only & 23 & $6 \mathrm{CR}, 1 \mathrm{PR}(30.4 \%)$ \\
EPOCH & 11 & $4 \mathrm{CR}$ \\
CHOP & 7 & $2 \mathrm{CR}, 1 \mathrm{PR}$ \\
CVP & 1 & 0 \\
Hyper CVAD & 4 & 0 \\
Chemotherapy with antiviral & 16 & $3 \mathrm{CR}, 3 \mathrm{PR}(37.5 \%)$ \\
EPOCH + Bortezomib + & 5 & $1 \mathrm{CR}, 2 \mathrm{PR}$ \\
Raltegravir & 1 & 0 \\
EPOCH + Lamivudine & 8 & $2 \mathrm{CR}, 1 \mathrm{PR}$ \\
EPOCH + Lamivudine / AZT & 1 & 0 \\
CHOP + AZT & 1 & 0 \\
Hyper CVAD + AZT & 2 & $0 \mathrm{CR}, 0 \mathrm{PR}(0 \%)$ \\
Other & 2 & 0 \\
IFN + AZT & & \\
\hline
\end{tabular}

EPOCH: etoposide, prednisone, vincristine, cyclophosphamide, doxorubicin; CHOP: cyclophosphamide, doxorubicin, vincristine, prednisone; CVP: cyclophosphamide, vincristine, prednisone; Hyper CVAD: hyperfractionated cyclophosphamide, vincristine, doxorubicin, dexamethasone; IFN: interferon alpha; AZT: zidovudine; CR: complete response; PR: partial response.

$(\mathrm{n}=41)$.

Table 5: Outcomes of allogeneic hematopoietic stem cell transplantation

\begin{tabular}{|c|c|c|c|c|c|}
\hline Patient & 1 & 2 & 3 & 4 & 5 \\
\hline Subtype & Acute & Acute & Acute & Acute & Lymphomatous \\
\hline Lines of therapy & 3 & 1 & 1 & 5 & 3 \\
\hline $\begin{array}{l}\text { Disease status pre- } \\
\text { transplant }\end{array}$ & PR & PR & CR & PD & PR \\
\hline Graft & Haplo & MRD & MUD & MRD & MRD \\
\hline $\begin{array}{l}\text { Conditioning } \\
\text { regimen }\end{array}$ & RIC & MA & RIC & RIC & RIC \\
\hline $\begin{array}{l}\text { Acute GVHD } \\
\text { (Grade) }\end{array}$ & Skin (2) & GI (4) & GI, Skin (1) & GI (1) & GI (4) \\
\hline Chronic GVHD & None & N/A & Skin & N/A & $\mathrm{N} / \mathrm{A}$ \\
\hline PFS & $14.4+$ & 1.4 & $17.2+$ & 3.7 & 3.4 \\
\hline OS & $25.7+$ & 7.6 & $28.4+$ & 10.4 & 47.2 \\
\hline
\end{tabular}

PFS is counted from day of stem cell infusion. OS is counted from index date. PR: partial response; CR: complete response; PD: progressive disease; Haplo: haploidentical donor; MRD: matched related donor; MUD: matched unrelated donor; RIC: reduced intensity conditioning; MA: myeloablative; GVHD: graft versus host disease; PFS: progression free survival; OS: overall survival.

unique as it describes the natural history, cytogenetics, and outcomes of front-line therapies and stem cell transplantation in a Caribbean ATLL cohort.

ATLL patients diagnosed in the Bronx have a higher incidence of acute and lymphomatous subtypes. The median age at diagnosis is 54 years and approximately $30 \%$ of patients have severe concurrent comorbidities/infections or are elderly, making them ineligible for intensive chemotherapy. Interestingly, no patients were co-infected with HIV; whether this is a true association is currently unknown. In this cohort there was a high prevalence of features of higher risk 
disease (hypercalcemia, high $\mathrm{LDH}$, and bone marrow involvement) [19]. The rate of CNS involvement in this population was as high as $33 \%$, supporting the argument for primary CNS prophylaxis at the time of diagnosis. Despite higher rates of CNS dissemination compared to previously reported incidence in other mature T-cell lymphomas $(4.5 \%)$ [21], mortality is primarily due to uncontrolled systemic disease. Flow cytometry showed a CD4+/CD8-, CD25+ CD7- T-cell population in most patients, reflecting the typical ATLL immunophenotype. In those with cytogenetic data available, all but three patients had complex karyotypes. Chromosome 14 was the most common chromosome involved, unlike in Japanese cohorts where deletions of chromosome 1 are more common [12]. These complex cytogenetics, markers of cumulative genetic events, and the presence of multiple cell subclones at the time of disease manifestation, likely explain why this disease is highly resistant to standard chemotherapy regimens. Moreover, the tumor suppressor p53 without mutations could be silenced by the pro-viral genome [22] and early and late ATLL could be driven by oncogene versus oncogenic microRNA addiction [23].

First-line chemotherapy for ATLL in the United States is most commonly an anthracycline-based regimen such as CHOP or EPOCH [24]. Multi-agent non-crossresistant chemotherapy regimens like LSG15 are not used due to non-availability of drugs like ranimustine and vindesine in the United States [25]. Our data suggest that the response to first-line regimens for ATLL is poor, with $68 \%$ of patients having progressive or primary refractory disease. Moreover, the achieved responses to these regimens are short-lived and a second remission is difficult to induce. These figures are lower than those reported by Phillips et al [26], but are consistent with historical data and the poor OS (median 6.9 months) of this population. Even though a prior meta-analysis shows benefit with antiviral agents [27], we did not observe any statistically significant difference between patients treated with chemotherapy alone versus chemotherapy and antiviral agents. Only three patients in this cohort were treated with IFN + AZT, and one patient with chronic subtype ATLL achieved a CR. However, the use of antivirals was a favorable factor in those who underwent allogeneic transplantation, and hence we continue to use antiviral therapy in the treatment of all ATLL, especially in the acute subtype.

Seven patients underwent stem cell transplantation. Of the five patients that underwent allo-HSCT, two had a long term $\mathrm{CR}$, still in remission at the time of this
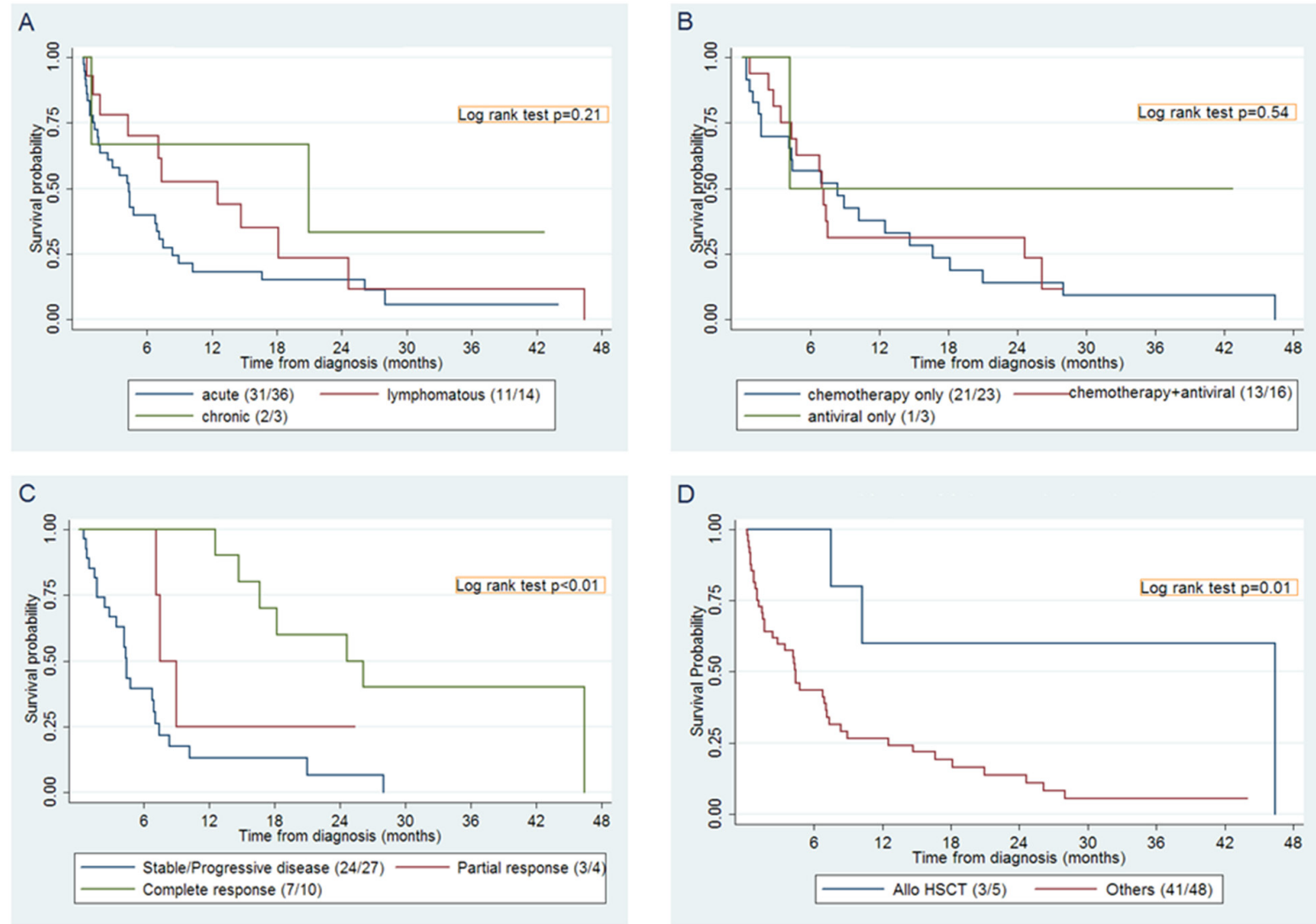

Figure 1: Survival in the ATLL Caribbean cohort. A. Overall survival by ATLL subtype B. Overall survival comparing first-line chemotherapy with antiviral agent versus first-line chemotherapy alone C. Overall survival response to first-line treatment D. Overall survival of patients with allogeneic hematopoietic stem transplant compared to overall cohort. HSCT: hematopoietic stem cell transplant; allo HSCT: allogeneic hematopoietic stem cell transplant. 
report. Unique features in both of these patients included: partially chemotherapy-responsive disease, treatment with antivirals as a part of the induction regimen, and maintenance on IFN+AZT prior to allo-HSCT. Whether these features have an impact on outcomes with alloHSCT in this population needs to be further investigated. Of the three patients who failed allo-HSCT, two had early relapses within 100 days. The disease responded to withdrawal of immunosuppression in one patient, suggesting a graft-versus-lymphoma effect, though the patient ultimately succumbed to GVHD. A recent non-Japanese ATLL study found improved outcomes in patients who underwent allo-HSCT in comparison to autologous transplant [17], and early application of HSCT may be beneficial [28]. The timing and patient selection for allo-HSCT remain controversial, as its utility could be limited in patients with progressive disease [29]. Based on our experience demonstrating a poor overall survival in these patients, and evidence of a graft vs. lymphoma effect, we propose allo-HSCT in an upfront setting. This would ideally be achieved after first-line treatment with at least a partial response. The conditioning regimen would then provide a window of opportunity for graft vs. lymphoma effects to be established. Autologous transplantation is considered to be ineffective in ATLL. Two patients in our cohort underwent autologous transplantation, with PFS of 13 months and nine months, which were higher than expected for this population. Hence, autologous transplantation may be an option in patients who have achieved at least a partial remission with initial chemotherapy and have evidence of chemosensitive disease. Whether this is related to patient selection or achieving a PR from initial therapy is not known. The OS of 6.9 months in our cohort is less than that of 8.3 and 10.6 months for acute and lymphomatous ATLL, respectively, reported in a larger Japanese cohort [30]. However, in the aforementioned study, $25 \%$ of patients who underwent HSCT had long term survival consistent with that of our cohort. The barriers to allogeneic transplantation in this population are 1) lack of matched related donors due to ethnicity, 2) progressive disease and poor response to first-line treatment, and 3) poor performance status due to recurrent infections. Since this was a retrospective analysis the true incidence of other subtypes of ATLL may not be reflected in this study. Moreover, this analysis is limited to a single institution and our experience with ATLL may differ from that of other institutions.

Currently, most studies impacting ATLL management involve Japanese patients. Our study provides insight into the problems faced by the ATLL population in the United States and should focus clinical trials to areas of need accordingly. Urgent clinical trials with improved front-line chemotherapy regimens, in combination with biological agents, are needed to achieve a better quality of response. Differences in HTLV viral load, TAX expression and TCR repertoire of Allo transplant patients in $\mathrm{CR}$ vs $<\mathrm{CR}$ may be suitable biomarkers to explore in future studies. Allogeneic stem cell transplant should be considered upfront. The timing of antivirals and continuing antivirals/interferon preand post-transplant needs to be evaluated. Additionally, T-cell adaptive immunotherapy should be explored in this disease.

\section{MATERIALS AND METHODS}

Patient records were queried using the Clinical Looking Glass ${ }^{\circledR}$ (CLG) software to identify all cases of HTLV positivity and ATLL by searching pathology and laboratory reports of patients who presented to Montefiore Medical Center (MMC) between 2003 and 2014. CLG is an interactive software application developed at MMC that integrates demographic, clinical, and administrative datasets and allows them to be reproduced in a programmable format for statistical access. Electronic medical records were manually reviewed to confirm diagnoses and for relevant data points. The diagnosis of ATLL was confirmed based on clinical history, pathological findings, and HTLV-1 antibody positivity. Cases were classified by subtype using the Shimoyama criteria [8]. Index date was defined as the date on which a diagnosis of ATLL was made. Demographic data as well as laboratory values, pathologic records, treatment records, outcomes, and survival were collected. Mortality data included death records within our institution as well as those reported by Social Security records. For patients who were discharged to hospice with confirmed documentation of refractory disease and unknown date of death $(n=5)$, date of discharge to palliative care was equated with date of death. All chart review was conducted by one of the study authors and discrepancies were reviewed by at least two authors. This research was approved by our institutional review board and ethics committee. All authors had access to the primary clinical data and were involved in data analysis.

\section{Statistical analysis:}

Data generated by CLG and complemented with individual chart review were transferred to a computer spreadsheet (Microsoft Excel, Microsoft Corp., Redmond, WA). For the analysis of categorical variables, we reported proportions and $\mathrm{p}$ values calculated with Pearson chi square or Fisher exact test as appropriate. Kaplan-Meier curves were used to compare survival and statistical significance was examined using the log rank test. Statistical analyses were performed with Stata v12 (StataCorp LP, College Station, TX) and a two-tailed alpha of 0.05 was used to denote significance. 


\section{CONFLICT OF INTEREST}

None of the authors have any conflict of interest to disclose.

\section{FUNDING}

None

\section{REFERENCES}

1. Uchiyama T, Yodoi J, Sagawa K, Takatsuki K, Uchino H. Adult T-cell leukemia: clinical and hematologic features of 16 cases. Blood. 1977; 50:481-492.

2. Hinuma Y, Nagata K, Hanaoka M, Nakai M, Matsumoto T, Kinoshita KI, Shirakawa S, Miyoshi I. Adult T-cell leukemia: antigen in an ATL cell line and detection of antibodies to the antigen in human sera. Proc Natl Acad Sci U S A. 1981; 78:6476-6480.

3. Poiesz BJ, Ruscetti FW, Gazdar AF, Bunn PA, Minna JD, Gallo RC. Detection and isolation of type $\mathrm{C}$ retrovirus particles from fresh and cultured lymphocytes of a patient with cutaneous T-cell lymphoma. Proc Natl Acad Sci U S A. $1980 ; 77: 7415-7419$.

4. Yoshida M, Miyoshi I, Hinuma Y. Isolation and characterization of retrovirus from cell lines of human adult T-cell leukemia and its implication in the disease. Proc Natl Acad Sci U S A. 1982; 79:2031-2035.

5. Goncalves DU, Proietti FA, Ribas JG, Araujo MG, Pinheiro SR, Guedes AC, Carneiro-Proietti AB. Epidemiology, treatment, and prevention of human T-cell leukemia virus type 1-associated diseases. Clin Microbiol Rev. 2010; 23:577-589.

6. Hisada M, Stuver SO, Okayama A, Li HC, Sawada T, Hanchard B, Mueller NE. Persistent paradox of natural history of human $\mathrm{T}$ lymphotropic virus type I: parallel analyses of Japanese and Jamaican carriers. J Infect Dis. 2004; 190:1605-1609.

7. Johnson JM, Harrod R, Franchini G. Molecular biology and pathogenesis of the human T-cell leukaemia/ lymphotropic virus Type-1 (HTLV-1). Int J Exp Pathol. 2001; 82:135-147.

8. Shimoyama M. Diagnostic criteria and classification of clinical subtypes of adult T-cell leukaemia-lymphoma. A report from the Lymphoma Study Group (1984-87). Br J Haematol. 1991; 79:428-437.

9. Fukushima T, Nomura S, Shimoyama M, Shibata T, Imaizumi Y, Moriuchi Y, Tomoyose T, Uozumi K, Kobayashi Y, Fukushima N, Utsunomiya A, Tara M, Nosaka K, et al. Japan Clinical Oncology Group (JCOG) prognostic index and characterization of long-term survivors of aggressive adult T-cell leukaemia-lymphoma (JCOG0902A). Br J Haematol. 2014; 166:739-748.
10. Katsuya H, Yamanaka $T$, Ishitsuka K, Utsunomiya A, Sasaki H, Hanada S, Eto T, Moriuchi Y, Saburi Y, Miyahara M, Sueoka E, Uike N, Yoshida S, et al. Prognostic index for acute- and lymphoma-type adult T-cell leukemia/ lymphoma. J Clin Oncol. 2012; 30:1635-1640.

11. Major prognostic factors of patients with adult T-cell leukemia-lymphoma: a cooperative study. Lymphoma Study Group (1984-1987). Leuk Res. 1991; 15:81-90.

12. Itoyama $\mathrm{T}$, Chaganti RS, Yamada $\mathrm{Y}$, Tsukasaki K, Atogami S, Nakamura H, Tomonaga M, Ohshima K, Kikuchi M, Sadamori N. Cytogenetic analysis and clinical significance in adult T-cell leukemia/lymphoma: a study of 50 cases from the human T-cell leukemia virus type-1 endemic area, Nagasaki. Blood. 2001; 97:3612-3620.

13. Kamada N, Sakurai M, Miyamoto K, Sanada I, Sadamori N, Fukuhara S, Abe S, Shiraishi Y, Abe T, Kaneko Y, et al. Chromosome abnormalities in adult T-cell leukemia/ lymphoma: a karyotype review committee report. Cancer Res. 1992; 52:1481-1493.

14. Oshiro A, Tagawa H, Ohshima K, Karube K, Uike N, Tashiro Y, Utsunomiya A, Masuda M, Takasu N, Nakamura S, Morishima Y, Seto M. Identification of subtype-specific genomic alterations in aggressive adult T-cell leukemia/ lymphoma. Blood. 2006; 107:4500-4507.

15. Tsukasaki K, Utsunomiya A, Fukuda H, Shibata $T$, Fukushima T, Takatsuka Y, Ikeda S, Masuda M, Nagoshi H, Ueda R, Tamura K, Sano M, Momita S, et al. VCAPAMP-VECP compared with biweekly CHOP for adult T-cell leukemia-lymphoma: Japan Clinical Oncology Group Study JCOG9801. J Clin Oncol. 2007; 25:5458-5464.

16. National Comprehensive Cancer Network. Non-Hodgkin's Lymphomas (Version 2.2015). Accessed March 17, 2015. http://www.nccn.org/professionals/physician_gls/pdf/nhl.pdf.

17. Bazarbachi A, Cwynarski K, Boumendil A, Finel H, Fields P, Raj K, Nagler A, Mohty M, Sureda A, Dreger P, Hermine O. Outcome of patients with HTLV-1-associated adult T-cell leukemia/lymphoma after SCT: a retrospective study by the EBMT LWP. Bone Marrow Transplant. 2014; 49:1266-1268.

18. Chihara D, Ito H, Matsuda $\mathrm{T}$, Katanoda K, Shibata A, Taniguchi S, Utsunomiya A, Sobue T, Matsuo K. Association between decreasing trend in the mortality of adult T-cell leukemia/lymphoma and allogeneic hematopoietic stem cell transplants in Japan: analysis of Japanese vital statistics and Japan Society for Hematopoietic Cell Transplantation (JSHCT). Blood Cancer J. 2013; 3:e159.

19. Tsukasaki K, Hermine O, Bazarbachi A, Ratner L, Ramos JC, Harrington W, Jr., O'Mahony D, Janik JE, Bittencourt AL, Taylor GP, Yamaguchi K, Utsunomiya A, Tobinai K, et al. Definition, prognostic factors, treatment, and response criteria of adult T-cell leukemia-lymphoma: a proposal from an international consensus meeting. J Clin Oncol. $2009 ; 27: 453-459$. 
20. Phillips AA, Willim RD, Savage DG, Horwitz SM, Isola L, Zain JM, O'Connor OA. A multi-institutional experience of autologous stem cell transplantation in North American patients with human T-cell lymphotropic virus type-1 adult T-cell leukemia/lymphoma suggests ineffective salvage of relapsed patients. Leuk Lymphoma. 2009; 50:1039-1042.

21. Ellin F, Landstrom J, Jerkeman M, Relander T. Central nervous system relapse in peripheral T-cell lymphomas: a Swedish Lymphoma Registry study. Blood. 2015; 126:36-41.

22. Wright DG, Marchal C, Hoang K, Ankney JA, Nguyen ST, Rushing AW, Polakowski N, Miotto B, Lemasson I. Human T-cell leukemia virus type-1-encoded protein HBZ represses $\mathrm{p} 53$ function by inhibiting the acetyltransferase activity of p300/CBP and HBO1. Oncotarget. 2015; 7:16871706. doi: 10.18632/oncotarget.6424.

23. Jeang KT. Human T cell leukemia virus type 1 (HTLV1) and oncogene or oncomiR addiction? Oncotarget. 2010; 1:453-456. doi: 10.18632/oncotarget. 179.

24. Zelenetz AD. Guidelines for NHL: updates to the management of diffuse large B-cell lymphoma and new guidelines for primary cutaneous CD30+ T-cell lymphoproliferative disorders and T-cell large granular lymphocytic leukemia. J Natl Compr Canc Netw. 2014; 12:797-800.

25. Yamada Y, Tomonaga M, Fukuda H, Hanada S, Utsunomiya A, Tara M, Sano M, Ikeda S, Takatsuki K, Kozuru M, Araki K, Kawano F, Niimi M, et al. A new G-CSF-supported combination chemotherapy, LSG15, for adult T-cell leukaemia-lymphoma: Japan Clinical Oncology Group Study 9303. Br J Haematol. 2001; 113:375-382.
26. Phillips AA, Shapira I, Willim RD, Sanmugarajah J, Solomon WB, Horwitz SM, Savage DG, Bhagat G, Soff G, Zain JM, Alobeid B, Seshan VE, O'Connor OA. A critical analysis of prognostic factors in North American patients with human T-cell lymphotropic virus type-1associated adult T-cell leukemia/lymphoma: a multicenter clinicopathologic experience and new prognostic score. Cancer. 2010; 116:3438-3446.

27. Bazarbachi A, Plumelle Y, Carlos Ramos J, Tortevoye P, Otrock Z, Taylor G, Gessain A, Harrington W, Panelatti G, Hermine O. Meta-Analysis on the Use of Zidovudine and Interferon-Alfa in Adult T-Cell Leukemia/Lymphoma Showing Improved Survival in the Leukemic Subtypes. J Clin Oncol. 2010; 28:4177-4183.

28. Fuji S, Fujiwara H, Nakano N, Wake A, Inoue Y, Fukuda T, Hidaka M, Moriuchi Y, Miyamoto T, Uike N, Taguchi J, Eto T, Tomoyose T, et al. Early application of related SCT might improve clinical outcome in adult T-cell leukemia/ lymphoma. Bone Marrow Transplant. 2016; 51:205-211.

29. Kawada H, Yoshimitsu M, Nakamura D, Arai A, Hayashida M, Kamada Y, Maekawa K, Fujino S, Arima M, Arima $\mathrm{N}$, Tabuchi $\mathrm{T}$, Inoue $\mathrm{H}$, Hamda $\mathrm{H}$, et al. A retrospective analysis of treatment outcomes in adult $\mathrm{T}$ cell leukemia/ lymphoma patients with aggressive disease treated with or without allogeneic stem cell transplantation: A singlecenter experience. Biol Blood Marrow Transplant. 2015; 21:696-700.

30. Katsuya H, Ishitsuka K, Utsunomiya A, Hanada S, Eto T, Moriuchi Y, Saburi Y, Miyahara M, Sueoka E, Uike N, Yoshida S, Yamashita K, Tsukasaki K, et al. Treatment and survival among 1594 patients with ATL. Blood. 2015; $126: 2570-2577$. 